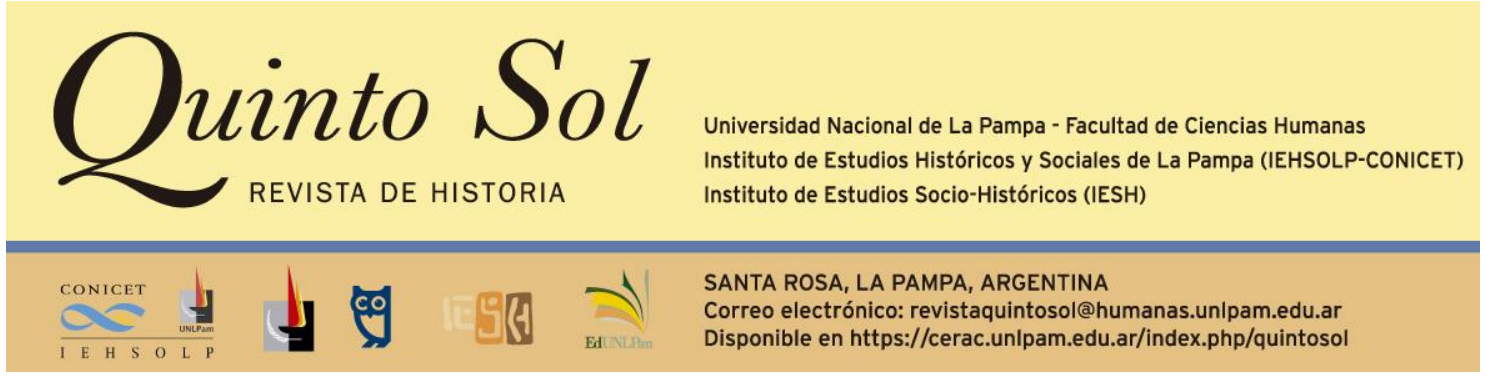

Quinto Sol, vol. 25, n 3, septiembre-diciembre 2021, ISSN 1851-2879, pp. 1-22

https://doi.org/10.19137/qs.v25i3.4381

Esta obra se publica bajo licencia Creative Commons 4.0 Internacional. (Atribución-No ComercialCompartir Igual)

\title{
Enemigos íntimos. Percepciones del marxismo y las izquierdas en Tacuara y sus agrupaciones derivadas
}

\author{
Intimate enemies. Perceptions of Marxism and the left in \\ Tacuara and its branch organizations
}

\section{Inimigos íntimos. Percepções do marxismo e as esquerdas em Tacuara e suas agrupações derivadas}

\section{Esteban Javier Campos}

Consejo Nacional de Investigaciones Científicas y Técnicas

Universidad de Buenos Aires. Instituto de Historia Argentina y Americana "Dr. Emilio Ravignani" Argentina

Correo electrónico: estebancampos1977@gmail.com

\section{Resumen}

El propósito de este artículo es comprender qué lugar ocuparon las representaciones del marxismo y las izquierdas en Tacuara y sus agrupaciones derivadas, como parte de una investigación más amplia sobre los grupos católicos, marxistas y nacionalistas que se identificaron con la izquierda peronista en los años sesenta. En el texto se plantea que el marxismo y las izquierdas eran representados como una alteridad radical investida de rasgos negativos, que operaba como exterior constitutivo de la propia identidad tacuarista. La teoría conspirativa del gobierno universal, o la batalla cultural entre el cristianismo y el materialismo, no podían funcionar sin el espectro del comunismo como amenaza permanente y multiforme. Del otro lado, los grupos nacionalistas querían imitar la eficacia atribuida al comunismo para infiltrar sociedades y colonizar conciencias. En este contexto, el concepto de lucha de clases fue problematizado por Tacuara e incorporado luego por algunos de sus fraccionamientos, lo que

Palabras clave identidad nacionalismo cultural Tacuara marxismo 
evidencia el desplazamiento de un nacionalismo culturalista a otro más secularizado. Para avanzar en estas formulaciones se analizará la prensa política de Tacuara y sus agrupaciones derivadas, como Tacuara. Vocero De La Juventud Nacionalista, Ofensiva, Barricada Del Nacionalismo Revolucionario, Tacuara del manchón y Nueva Argentina, entre otros documentos.

\section{Abstract}

The purpose of this article is to understand what place the representations of Marxism and the left occupied in Tacuara and its branch organizations, as part of a broader investigation of the Catholic, Marxist and nationalist groups identified with the Peronist left in the '60s. The text states that Marxism and the left were represented as a radical otherness with negative features, which operated as a constitutive exterior of the tacuarist identity itself. The conspiracy theory of universal government, or the cultural battle between Christianity and materialism, could not function without the specter of communism as a permanent and multiform threat. On the other hand, nationalist groups wanted to imitate the efficiency attributed to communism to infiltrate societies and colonize consciences. In this context, the concept of class struggle was problematized by Tacuara, and then incorporated by some of its subdivisions, which evidences the displacement of a culturalist nationalism to a more secularized one. To advance these formulations, will be analyzed the political press of Tacuara and its derivative groups, such as Tacuara. Vocero De La Juventud Nacionalista, Ofensiva, Barricada Del Nacionalismo Revolucionario, Tacuara del manchón y Nueva Argentina, among other documents.

\section{Resumo}

O propósito deste artigo é compreender que lugar ocuparam as representações do marxismo e as esquerdas em Tacuara e suas agrupações derivadas, como parte de uma investigação mais ampla sobre os grupos católicos, marxistas, nacionalistas que se identificaram com a esquerda peronista nos anos sessenta. No texto, expõe-se que o marxismo e as esquerdas eram representados como uma alteridade radical com traços negativos, que operava como exterior constitutivo da própria identidade tacuarista. A teoria conspirativa do governo universal, ou a batalha cultural entre o cristianismo e o materialismo, não podiam funcionar sem o espectro do comunismo como ameaça permanente e multiforme. Por outro lado, os grupos nacionalistas queriam imitar a eficácia atribuída ao comunismo para infiltrar sociedades e colonizar consciências. Neste contexto, o conceito de luta de classes foi problematizado por Tacuara e incorporado depois por alguns de seus fraccionamentos o que evidencia o deslocamento de um nacionalismo culturista para outro mais secularizado. Para avançar nestas formulações se analisará a imprensa política de Taquara e suas agrupações derivadas, como Tacuara. Vocero De La Juventud Nacionalista, Ofensiva, Barricada Del Nacionalismo revolucionario, Tacuara del manchón e Nueva Argentina, entre outros documentos.

Recepción del original: 10 de febrero de 2020.

Aceptado para publicar: 01 de diciembre de 2020.

\section{Keywords}

identity

cultural nationalism

Tacuara

Marxism

\section{Palavras-chave}

identidade nacionalismo cultural

Tacuara

marxismo 


\section{Enemigos íntimos. Percepciones del marxismo y las izquierdas en Tacuara y sus agrupaciones derivadas ${ }^{1}$}

Hacia 1962, en su "Diálogo con los jóvenes fascistas", el periodista Rogelio García Lupo (1962) expresó sin ambages su desconcierto frente a los militantes del Movimiento Nacionalista Tacuara (MNT), ya que "éstos, además de antisemitas y anticomunistas, son violentamente antiyanquis" (p. 69). En el contexto de la Guerra Fría y la polarización de las fronteras ideológicas trazadas entre Estados Unidos y la Unión Soviética, la convergencia de estas definiciones parecía fuera de lugar. La dificultad para clasificar a estos jóvenes activistas era coetánea a los diversos fraccionamientos que se produjeron en la Tacuara originaria. Un informe de inteligencia de la policía bonaerense, fechado el 31 de mayo de 1960, sostenía que la organización no era nazi ni fascista, sino que seguía "una línea concordante con la 'falanje española' [sic], aceptando solo el resurgimiento argentino a través de una dictadura depuradora especialmente en el campo gremial donde sería de aplicación un Régimen Nacional Sindicalista". ${ }^{2}$ Tres años después, un documento de la misma factura indicaba que el MNT "tiene un Secretario General cuyo titular es José Baxter, quien se autodefine como nacionalista filo-comunista". ${ }^{3}$ Los grandes medios de prensa también se hicieron eco de estas variaciones, como indica una nota del diario La Razón. Allí se informaba que en un allanamiento a miembros del Movimiento Nacionalista Revolucionario Tacuara (MNRT), se habían encontrado "volantes con lemas nacionalistas y libros con la doctrina peronista y obras sobre la personalidad de Stalin y Khruschev". ${ }^{4}$ En abril, otra nota citaba un informe de Coordinación Federal para señalar que Tacuara se dividía en tres nucleamientos: "uno de derecha, dirigido por Alberto Ezcurra, nacionalista; uno de izquierda, dirigido por José Baxter, marxista insurreccional, castrista y pro chino, y un tercer grupo dirigido por Alfredo Ossorio, nacionalista en lo político pero fuertemente izquierdizante" (Bardini, 2002, p. 97). Finalmente, la periodista María Cristina Verrier sostenía en la revista Panorama que "algunos tacuaras se pronuncian como justicialistas" (Bardini, 2002, pp. 61-63). Era el caso del Movimiento Nueva Argentina (MNA), cuyos integrantes se habían desempeñado en 1965 como parte de la custodia de Isabel Martínez de Perón en su viaje a Argentina.

El interés de este trabajo es comprender qué lugar ocuparon las representaciones del marxismo y las izquierdas en Tacuara y sus agrupaciones derivadas, ya que indagar el desplazamiento de estas percepciones habilita un mejor

\footnotetext{
${ }^{1}$ Este artículo no hubiera sido posible sin la generosidad de Luis Herrán Ávila, Gabriel Rot y Juan Luis Besoky, quienes me facilitaron varios de los documentos analizados en el presente trabajo.

2 Colección 2 "Movimiento Nacionalista Tacuara (1962-1976)", folio 5. Comisión Provincial por la Memoria (CPM), Archivo de la Dirección de Inteligencia de la Provincia de Buenos Aires (DIPBA), Argentina.

${ }^{3}$ Colección 2, folio 12 .

${ }^{4}$ El país ante un suceso de extraordinaria gravedad (24 de marzo de 1964). La Razón (s.p.). Colección 2, folios 358-359.
} 
conocimiento de los grupos nacionalistas que se identificaron con la izquierda peronista en los años sesenta. Las migraciones militantes de Tacuara hacia el peronismo desplazaron los límites del comunismo como aquel gran "otro" que permitía diferenciar la propia identidad, y adaptaron las representaciones del enemigo rojo a los nuevos tiempos del orden bipolar, el tercermundismo y los nacionalismos de izquierda. Algunos tacuaristas realizaron una apropiación selectiva del vocabulario marxista y se acercaron a grupos izquierdistas, mientras que otros conservaron la matriz anticomunista y antimaterialista de la Tacuara originaria. Para avanzar en este planteo se analizará la prensa política del MNT, como el periódico Tacuara. Vocero De La Juventud Nacionalista y el boletín Ofensiva, las publicaciones del MNRT Barricada Del Nacionalismo Revolucionario y Tacuara del manchón, y la prensa oficial del MNA, Nueva Argentina. A esta muestra se suman volantes, entrevistas e informes de inteligencia provenientes del archivo del Centro de Documentación e Investigación de la Cultura de Izquierdas en Argentina (CEDINCI), de la Dirección de Inteligencia de la Policía de la Provincia de Buenos Aires (DIPBA) y del sitio web El Topo Blindado. Centro de documentación de las organizaciones político-militares argentinas.

Tacuara fue una organización nacionalista que logró una importante exposición pública por sus prácticas antisemitas y anticomunistas. Sus orígenes se remontan a un puñado de militantes provenientes de la Unión Nacionalista de Estudiantes Secundarios, que participaron como comandos civiles en el golpe militar que derrocó a Juan Domingo Perón. La ideología del MNT encontraba sus principales referencias en la derecha argentina y europea de entreguerras: el falangismo de José Antonio Primo de Rivera, el nacional-sindicalismo de Ramiro Ledesma Ramos, el revisionismo histórico, el antisemitismo del padre Julio Meinvielle y el comunitarismo de Jacques-Marie de Mahieu, un intelectual francés con simpatías nazis que criticaba la propiedad privada y la plusvalía. A partir de la intervención en el conflicto conocido como "laica o libre", a favor de la legalización de las universidades católicas, el MNT creció en número y amplió su composición social. El núcleo originario, vinculado a jóvenes de familias patricias que predicaban un nacionalismo cultural de tintes hispanistas y católicos, fue desbordado por la llegada de nuevos militantes más preocupados por la cuestión social, de perfil plebeyo y afinidades peronistas, lo que terminó por fracturar la organización.

En octubre de 1960, un grupo cercano al padre Meinvielle, disgustado por la creciente influencia de De Mahieu, se separó para fundar la Guardia Restauradora Nacionalista, tras denunciar que Tacuara había sido conquistada por el fidelismo, el trotskismo y el ateísmo (Padrón, 2017). En junio de 1961, siete activistas rompieron con Ezcurra Uriburu para crear el MNA, que se proclamó parte del movimiento peronista y se acercó a sindicalistas como José Alonso y Augusto Timoteo Vandor. El grupo dirigido por Dardo Cabo, hijo del dirigente de la CGT Armando Cabo, empleó un discurso nacionalista cuyas notas más estridentes eran el justicialismo, el anticomunismo y el antisionismo, pero se hizo más conocido por sus acciones: en agosto de 1964, un comando del MNA interrumpió con disparos y bombas de estruendo una cena en homenaje al expresidente Arturo Frondizi, atentado que generó un acalorado debate en el Congreso Nacional (Ruffini, 2016). Dos años más tarde, un 
grupo armado que incluía a varios militantes del MNA secuestró un avión comercial y lo desvió hacia las Islas Malvinas, donde se desplegaron varias banderas argentinas.

En el último tercio de 1962 se consumó la ruptura del MNRT, a partir de un grupo liderado por José Luis Nell, Joe Baxter y Alfredo Ossorio, que se definía peronista, reivindicaba un socialismo nacionalista y se organizaba clandestinamente para la lucha armada. Varios meses después, Ossorio y sus seguidores se agruparon en torno al periódico Barricada Del Nacionalismo Revolucionario, al percibir un giro a la izquierda del sector que tenía como principal vocero a Baxter. Esta nueva fractura se explica por el intento de construir una identidad propia en base a las ideas comunitaristas de De Mahieu, que tomaba distancia de un nacionalismo cuestionado por su elitismo y conservadurismo, pero también se reivindicaba alternativa a una izquierda que, desde el punto de vista de esta fracción, pretendía infiltrarse en el movimiento nacional. El grupo conducido por Baxter y Nell publicó su propio órgano de prensa, conocido como Tacuara del manchón, y compartía con el sector de Ossorio las críticas a dirigentes nacionalistas como Ezcurra Uriburu, Meinvielle y Mario Amadeo, a quienes les atribuían opiniones elitistas y contrarrevolucionarias. Sin embargo, esta fracción del MNRT renegó públicamente del antisemitismo, se acercó a la Juventud Revolucionaria Peronista de Gustavo Rearte y cultivó buenas relaciones con marxistas como Ismael Viñas, Ricardo Rojo y Mario Valotta (Gutman, 2003). En agosto de 1963, un comando asociado a este sector asaltó el Policlínico Bancario del barrio de Caballito, con un saldo de dos muertos, tres heridos y un botín equivalente a 100.000 dólares, pero una investigación policial llevó a una ola de arrestos que terminó por disolver la agrupación. En la cárcel, varios tacuaristas como Jorge Caffatti, Carlos Arbelos y Alfredo Roca se acercaron al marxismo $y$, tras ser liberados, continuaron su militancia en las Fuerzas Armadas Peronistas. Joe Baxter nunca fue capturado y se convirtió en un activista internacional que visitó a Perón en Madrid hasta recalar finalmente en el PRTERP. José Luis Nell protagonizó una inédita fuga de Tribunales, militó con el MLNTupamaros en Uruguay y más tarde se incorporó a Montoneros.

\section{Comunismo y conspiración}

Tacuara se autodefinía como una organización nacionalista revolucionaria que no era de izquierda ni de derecha. En palabras de su jefe, Alberto Ezcurra Uriburu, "nosotros no queremos ni una cosa ni la otra, sino una síntesis de ambas... queremos una revolución social; pero con el signo de Dios y la bandera de la Patria". ${ }^{5}$ Como parte de estas concepciones, el anticomunismo fue un elemento medular de la ideología tacuarista, que echaba raíces en la tradición antimoderna católica, el nacionalismo de entreguerras y las renovadas ansiedades contrarrevolucionarias de la Guerra Fría (Bohoslavsky y Vicente, 2014). En un artículo redactado para el boletín Ofensiva, Pedro Otaño señalaba que "una cosa debe quedar clara: el comunismo en cualquiera de sus formas es el enemigo número uno". ${ }^{6}$ La amenaza comunista era global, y en la prensa del MNT tomaba la forma de una extensa trama conspirativa:

\footnotetext{
${ }^{5}$ Los tacuaristas no somos asesinos, afirma su jefe (4 de abril de 1964). Crónica (s.p.). Colección 2, folio 308.

${ }^{6}$ Otaño, P. (s.f.). Fagocitosis al revés. Ofensiva, s.f., pp. 4-6. Archivo del autor.
} 
Es muy difícil poder coordinar el cúmulo de documentos y hechos reales que comprueban el peligro que para los pueblos significaría la implantación del Gobierno Universal, meta de la revolución mundial comunista... Existe un vasto plan para controlar el mundo y llevarlo a la esclavitud. Los antecedentes de este plan internacional están a la vista. Quien no quiere ver, quien permanece indiferente y elude su consideración, atrae sobre sí bien fundadas sospechas de complicidad. ${ }^{7}$

Para Gerardo Valenzuela, un militante de Tacuara que terminó convirtiéndose en dirigente de la Guardia Restauradora Nacionalista, entidades supranacionales como la Organización de las Naciones Unidas (ONU) y el Fondo Monetario Internacional (FMI) eran los mascarones de proa de una ofensiva que tenía como fin el gobierno universal a través del caos, la guerra civil y la revolución socialista. Instituciones como la ONU y su predecesora, la Sociedad de las Naciones, habrían sido "trazadas sobre el Manifiesto Comunista". Varios de los artículos de la Carta de las Naciones Unidas se inspirarían en la constitución soviética, y sus redactores provendrían de una "camarilla pro-comunista" asociada a Harry Dexter White, fundador del FMI y "uno de los tres principales espías comunistas en los Estados Unidos". Por otra parte, la carta de la ONU no hacía más que escamotear:

toda alusión a la dependencia del hombre frente a Dios; en ninguna de sus partes puede hallarse una sola palabra que invoque a la guía Divina. Esta omisión no ha sido accidental, fue planeada así para agradar a los anticristos de Moscú y a sus incautas víctimas. $^{8}$

Otro rasgo de la conspiración era su carácter difuso, ya que no se movía solamente en las cumbres, sino también al ras del suelo, con una potencia capaz de configurar un nuevo modo de vida para las desprevenidas masas:

Las fuerzas ocultas, sobreestatales, aquellas que tienen como instrumentos ciegos los títeres que se mueven tanto en la Casa Blanca de Washington como en el Kremlin de Moscú, en la Downing Street 10 de Londres, en Bonn o en Roma; aquellas fuerzas ocultas que con dineros y cerebros son las dueñas exclusivas de las grandes agencias noticiosas y con ello de la prensa: dueñas exclusivas de aquellas fábricas modernas de sueños estupefacientes que son las industrias cinematográficas; dueñas exclusivas de las escuelas y universidades, de las radios y la T.V., de todos estos medios satánicos para sojuzgar el cerebro de la masa, para esclavizar la opinión pública y uniformarla en una operación diabólica; estas fuerzas ocultas que hoy imponen al $95 \%$ de la población "civilizada" el uso de un jabón de tocador determinado, para imponer mañana una idea política determinada, una guerra, un odio o un sentimentalismo. ${ }^{9}$

\footnotetext{
${ }^{7}$ Valenzuela, G. (1960). El gobierno universal. Tacuara. Vocero De La Juventud Nacionalista, XV (9) p. 3. Archivo del autor.

${ }^{8}$ Valenzuela, G. (1960). El gobierno universal. Tacuara. Vocero De La Juventud Nacionalista, XV(9), p. 3.

9 Nuestra zarza ardiente. (1959). Tacuara. Vocero De La Juventud Nacionalista, XIV (7), p. 1. https://eltopoblindado.com/nacionalismo-derecha/decada-1960-nacionalismo-derecha/tacuara/tacuarano-07-vocero-de-la-revolucion-nacionalista/
} 
Como sucedía en el cuento de Jorge Luis Borges Tlon, Uqbar, Orbis Tertius, aquí el complot se termina confundiendo con la realidad misma: podía manifestarse en un artículo de consumo cotidiano, en un presentador de noticias televisivas o en la película exhibida en una sala de cine. Para las ciencias humanas, el discurso de la conspiración mundial es una forma específica de producir conocimiento y de intervenir políticamente, una teoría apta para todo público que opera como simplificación cognitiva de sistemas complejos (Jameson, 1995; Piglia, 2001). El conspiracionismo postula que el motor de la historia es la acción secreta de un pequeño grupo de hombres con un proyecto de dominación que opera a escala planetaria. Los denunciadores de complots se esfuerzan por revelar los signos visibles de la trama que intentan camuflar los conjurados; así establecen correlaciones fácticas entre hechos, personas y discursos, que se sobreinterpretan como evidencia de una red virtualmente infinita. La "camarilla procomunista" escondida detrás de la ONU y el FMI sustituye a los actores sociales y las estructuras como claves de las dinámicas sociopolíticas globales. En última instancia, la tesis complotista de que las sociedades son manipuladas y gobernadas por poderes externos es una creencia religiosa secularizada, que reproduce la vieja ideología del despojo de las acciones humanas por una autoridad superior (Taïeb, 2010).

Un ingrediente esencial del conspiracionismo tacuarista era la denuncia de la complicidad entre los Estados Unidos y la Unión Soviética, que se correspondía con la autoconstrucción del grupo de Ezcurra Uriburu como una vanguardia alternativa a las derechas y las izquierdas. Para la prensa del MNT, el vínculo que unía a norteamericanos y soviéticos era el materialismo, por eso la América hispana renegaba de "la opción falsa en la que intentan someternos los dos bloques, aparentemente antagónicos, pero esencialmente idénticos que se disputan el dominio del mundo". ${ }^{10}$ Esta definición se repite en un artículo firmado por Carlos Falchi, que publicó Tacuara. Vocero De La Juventud Nacionalista hacia 1960:

El mundo está dividido en dos bloques, por un lado el Comunismo, por otro el Capitalismo, que se combaten y esclavizan respectivamente a media humanidad, pero están de acuerdo en el punto fundamental del marxismo, el materialismo histórico. Existen diferencias, sí, pero no en lo sustancial. Ambas son simplemente dos etapas distintas en la evolución hacia el Comunismo. Los occidentales están en la penúltima etapa, la del imperialismo, mientras los orientales andan ya por la última, el "Super capitalismo de Estado". ${ }^{11}$

Para Falchi, comunismo y capitalismo se solapaban como etapas históricas sucedáneas, pero también integraban un mismo código genético presente en el torrente sanguíneo de cada sistema. Si detrás de la cortina de hierro existía un supercapitalismo de Estado, las democracias occidentales alentaban la formación de los monopolios, que generarían las condiciones de descomposición social para el advenimiento del comunismo. En una cita del boletín Ofensiva, el publicista de Acción Francesa Henry Coston sostenía que "el supercapitalismo es el furriel del bolchevismo.

\footnotetext{
${ }^{10}$ La democracia no sirve (1963). Tacuara. Vocero de la juventud nacionalista, XVIII (s.n.), pp. 1-3.

${ }^{11}$ Falchi, C. (1960). Anticomunismo, en Tacuara. Vocero de la juventud nacionalista, XV(8), p. 4.
} 
Al destruir los cuadros de la economía tradicional, al mismo tiempo que las instituciones seculares de la Cristiandad, facilita el reclutamiento de las organizaciones controladas por el Kominform". ${ }^{12}$

La impugnación de las izquierdas en el MNA se remontaba a la tradición de la derecha nacionalista, pero también tendía puentes con el anticomunismo arraigado en importantes sectores del movimiento peronista y la clase obrera (Acha, 2014; Besoky, 2017). Como ocurría con la Tacuara originaria, los novoargentinos creían que el marxismo era un supercapitalismo de naturaleza apátrida, atea y reaccionaria. ${ }^{13} \mathrm{De}$ nuevo, capitalismo y comunismo eran tácticas de la "plutocracia internacional" que formaban parte de una conspiración para implantar el gobierno mundial:

Lenin es citado como habiendo dicho que el socialismo internacional es imposible sin un sistema económico internacional. Este sistema económico internacional está en proceso de ser llevado a la realidad. $Y$ un sistema financiero internacional es el principal mecanismo usado para promover este proceso. Nosotros observamos recientemente que el creciente "acuerdo" entre los países comunistas y no-comunistas es en los hechos, principalmente, una política de subvencionar a los comunistas por los no comunistas: las realidades de la situación son oscurecidas por la ortodoxia financiera. Ahora viene el dramático anuncio del presidente Johnson que hay una llave abierta en la política americana hacia el este europeo, países miembros del bloque comunista. Esta es una intensificación del camino hacia el Gobierno Mundial. ${ }^{14}$

Para el MNA, las finanzas internacionales eran vehículos de la expansión comunista en todo el globo, tendencia que se demostraría por el aumento de las relaciones comerciales entre Estados Unidos y la Unión de Repúblicas Socialistas Soviéticas (URSS). ${ }^{15}$ Los tentáculos de la hidra comunista se extendían en todos los estamentos de la sociedad argentina; en el periódico Nueva Argentina, el MNA llamaba la atención sobre "un poderoso aparato marxista de corrupción" que operaba en el país a través de la Confederación General Económica de José Ber Gelbard, la Minera Aluminé, el Instituto Movilizador de Fondos Cooperativos y la Federación Argentina de Cooperativas de Crédito. ${ }^{16}$ Desde el punto de vista de la organización, el Estado debía disolver estas instituciones en manos de comunistas y sionistas, responsables de promover la subversión en Argentina. A tono con estas iniciativas, también exigían una política de mano dura con las universidades para "eliminar a los profesores, materias y programas marxistas", así como erradicar a la izquierda del periodismo, la radio, el cine y la televisión. ${ }^{17}$ En el artículo "Bases para una estrategia justicialista", publicado por

\footnotetext{
${ }^{12}$ Henry Coston (diciembre de 1962). Ofensiva, n. 12, p. 3. Archivo del autor.

13 Reportaje al MNA (1961), p. 2. https://eltopoblindado.com/nacionalismo-derecha/decada-1960nacionalismo-derecha/movimiento-nueva-argentina/reportaje-al-mna/

${ }^{14}$ Una nueva fase en la conspiración mundial. Extracto del Boletín informativo del Movimiento Nueva Argentina (s.f.). https://eltopoblindado.com/nacionalismo-derecha/decada-1960-nacionalismoderecha/movimiento-nueva-argentina/nueva-fase-conspiracion-mundial/

15 Boletín informativo del Movimiento Nueva Argentina (febrero de 1965), n. 2, pp. 1-2. https://eltopoblindado.com/nacionalismo-derecha/decada-1960-nacionalismo-derecha/movimientonueva-argentina/boletin-informativo-2

${ }^{16}$ El poder marxista (1966). Nueva Argentina, n. 15, p. 2. Archivo del autor.

${ }^{17}$ Volante Movimiento Nueva Argentina-Para servir a la patria (s.d.). Archivo de Juan Luis Besoky, La Plata,
} 
Nueva Argentina, se consideraba que el "imperialismo bolchevique" era peor que su par británico del siglo XIX, ya que este solo se interesaba por los mercados, mientras el primero era un imperio ideológico que buscaba la conquista de las almas. Sin embargo, el mismo texto establecía una clara diferencia entre el marxismo de Lenin, que "se estrellaba con la realidad y amenazaba ahogarse en un abismo de sangre", y el "genio bonapartista de Stalin", que reconcilió "la revolución con la patria, la revolución con la realidad existente". ${ }^{18}$ Aun si se tiene en cuenta este detalle, el MNA hizo gala de un discurso anticomunista tanto o más virulento que el de la Tacuara originaria.

Dentro del MNRT, el grupo capitaneado por Ossorio profundizó la crítica al modelo social de la Unión Soviética. En Barricada Del Nacionalismo Revolucionario, por ejemplo, se cuestionaba al "mastodonte soviético, el Estado colectivista, que reúne en sus manos los medios de producción, de difusión y de coacción y somete a todo el cuerpo social a los intereses y apetitos de la 'nueva clase' burocrática". ${ }^{19}$ En otro artículo, Luis Peña definía al "estatismo soviético, mal llamado comunismo", como un capitalismo de nuevo tipo que había evolucionado de la crisis del liberalismo, hasta llegar a la formación de un "trust único y omnipotente, como Marx había profetizado". ${ }^{20}$ La burocracia de la URSS se había convertido en una nueva oligarquía, responsable de proletarizar a las clases medias y quedarse con la plusvalía del conjunto de los trabajadores. El "sistema marxista", entonces, no era una alternativa al capitalismo individualista, sino una reformulación del régimen explotador que agravaba sus consecuencias. A diferencia de la trama discursiva desarrollada por el MNT y el MNA, en estos pasajes, la denuncia de la complicidad entre Estados Unidos y la URSS se desplazaba de las teorías conspirativas a la crítica de la sociedad soviética. El cambio expresaba una mayor preocupación por el debate programático, que interpelaba desde la utopía comunitarista de Jacques De Mahieu al modelo de planificación centralizada, adoptado por países de la constelación tercermundista como Cuba y Argelia. Pero además, Ossorio y sus partidarios trataban de establecer una clara "frontera ideológica" frente al campo de las izquierdas, en un momento en el que los medios de comunicación señalaban al MNRT como una fracción de Tacuara al servicio del comunismo internacional. ${ }^{21}$

El ala del MNRT que respondía a Baxter y Nell también creía que derechas e izquierdas eran manifestaciones de los dos imperialismos, la primera por su "odio natural hacia lo popular", y la segunda "por su ignorancia supina de lo nacional". ${ }^{22} \mathrm{Sin}$

\footnotetext{
Argentina.

${ }^{18}$ Bases para una estrategia justicialista (1965). Nueva Argentina, n. 10, p. 2.

${ }^{19}$ L. G. (noviembre de 1963). Nuestra Revolución. Barricada Del Nacionalismo Revolucionario n. 2, p. 3. https://eltopoblindado.com/nacionalismo-derecha/decada-1960-nacionalismo-derecha/movimientonacionalista-de-restauracion/barricada-no-02/ En el mismo periódico se repiten las acusaciones de complicidad entre capitalistas y comunistas, ver Entre chanchos anda la cosa. (octubre de 1963). Barricada Del Nacionalismo Revolucionario, n. 1, p. 3. https://eltopoblindado.com/nacionalismo-derecha/decada1960-nacionalismo-derecha/movimiento-nacionalista-de-restauracion/barricada-no-01

20 Peña, L. (diciembre de 1963). Capitalismo blando, capitalismo fuerte. Barricada Del Nacionalismo Revolucionario, n. 4, p. 2. Archivo del autor.

21 Variante: una Tacuara izquierdista. (26 de septiembre de 1963). Primera Plana, n. 55. CEDINCI, Ciudad Autónoma de Buenos Aires, Argentina.

22 Perón o colonia (1964). Tacuara del manchón, n. 7, p. 1. Archivo del autor.
} 
embargo, el periódico Tacuara del manchón realizó una valorización de la Revolución rusa difícil de encontrar en otros medios de prensa tacuaristas, que solían considerarla como una declinación perversa y antinacional del liberalismo revolucionario iniciado en 1789:

Mientras en Rusia los bolcheviques tomaban el poder 7 años después que nosotros celebráramos el centenario con bombos y platillos, la Argentina cipaya seguía su rumbo con esa tranquila subordinación que solo tienen las burguesías suicidas. El apetito insaciable del Imperialismo nos sometía cada vez más a su insolencia explotadora. Mientras en Europa los fascismos levantaban juventudes que destruirían los últimos reductos de las democracias, y se acababa con los viejos mitos del pluralismo político y del sufragio universal, con la instauración del Partido Único en Rusia, Alemania e Italia, el país oficial iba sintiendo cada vez con mayor intensidad la presencia silenciosa pero tenaz de los no resignados. ${ }^{23}$

La relectura del "Octubre Rojo" de 1917 en clave nacionalista anudaba en una misma cadena de equivalencias a los bolcheviques y las experiencias fascistas de Europa occidental, con el antiliberalismo como denominador común. Lo distintivo del grupo que asaltó al Policlínico Bancario es que en sus volantes, sus entrevistas y su prensa política no había rastros de las viejas teorías conspirativas ni se denunciaba la connivencia entre soviéticos y norteamericanos. Estas nuevas prácticas de legitimación, y el vínculo con conocidos militantes de izquierda eran señales de que "el comunismo en cualquiera de sus formas" ya no era el enemigo número uno para este sector del MNRT.

Los conceptos vertidos sobre el comunismo en Tacuara y sus agrupaciones derivadas pueden verse como la construcción de una alteridad radical investida de atributos negativos, que operaba como exterior constitutivo de la propia identidad nacionalista. Sin embargo, en los documentos aparece algo más, el deseo de sustituir o imitar aquel poder desmesurado que, por un lado, formaba parte de los atributos negativos (la eficacia global del comunismo para colonizar conciencias), pero al mismo tiempo se revelaba como un fin o aspiración de las diversas Tacuaras. Para Ezcurra Uriburu, el marxismo "está a la altura de su misión y los nacionalistas no lo estamos todavía, pese a que el terreno de la Patria es más dócil a nuestra siembra que a la de ellos", ${ }^{24}$ mientras que, en opinión de Oscar Denovi -también militante del MNT-, a la hora de infiltrar una fuerza política, "el partido comunista, que tiene algo que enseñarnos en la materia, no quema etapas", enseñanza que podía utilizarse para atraer el movimiento peronista a la órbita del nacionalismo. ${ }^{25}$

El sector Ossorio del MNRT compartía el mismo diagnóstico de la Tacuara

\footnotetext{
${ }^{23}$ Perón o colonia (1964). Tacuara del manchón, n. 7, p. 1. El MNRT-Ossorio, en cambio, consideraba que el 17 de octubre "pudo seguir las huellas de aquel otro octubre estepario y oriental. Sin embargo, el trapo rojo fue pisoteado por las muchedumbres", ver Tercera posición (diciembre de 1963). Barricada Del Nacionalismo Revolucionario, n. 4, p. 4.

${ }^{24}$ Ezcurra Uriburu, A. (1960). Carnaval de entrega. Tacuara. Vocero De La Juventud Nacionalista, XV (8), p. 3. 25 Denovi, O. (noviembre de 1962). Tacuara y la técnica de la infiltración. Ofensiva, n. 11, p. 7. https://eltopoblindado.com/nacionalismo-derecha/decada-1960-nacionalismo-derecha/tacuara/ofensivano-11/
} 
originaria sobre la superioridad de las izquierdas, ya que "los marxistas, y esto no constituye un secreto para nadie, nos llevan la delantera y por el medio de la guerra revolucionaria dirigen la acción hacia la encrucijada de la historia". ${ }^{26}$ No obstante, en la misma nota, el periódico Barricada Del Nacionalismo Revolucionario iba más allá, y se apropiaba de las lecciones del marxismo sobre filosofía de la praxis:

Ante el gran escándalo del mundo, Lenin proclamó enfáticamente "la verdad es la acción", que sería desde entonces la divisa práctica del marxismo; ninguna mente equilibrada creerá el disparate filosófico, pero detrás de la barrabasada hay algo de cierto: por más que la concepción doctrinaria sea excelente, si no media una táctica previa científicamente delimitada y de rigurosa ejecución, no se logra tomar el poder... Mao Tse Tung lo confirma en sus páginas escogidas, diciendo: "Desde el punto de vista marxista, la teoría es importante, y su importancia lo demuestra claramente la afirmación de Lenin: sin una teoría revolucionaria no podrá haber un movimiento revolucionario. Pero el marxismo subraya la importancia de la teoría precisa y solamente porque puede orientar la acción. ${ }^{27}$

De acuerdo con el autor, el "nacionalismo bravucón" de Ezcurra Uriburu y el nacionalismo de "especulaciones metafísicas" de los intelectuales separaban la práctica de la teoría, mientras que el marxismo ofrecía un ejemplo acerca de cómo librar una guerra revolucionaria. La imitación y la sustitución, es decir, la enunciación de la oportunidad de arrebatarle banderas al enemigo no aparece en los documentos del MNA, tal vez porque el peronismo ofrecía un nicho identitario que volvía prescindible la necesidad de copiar los métodos del comunismo para obtener resultados revolucionarios. En el caso del MNRT, el vocabulario marxista terminó por desplazar al nacionalismo cultural predominante en el MNT y muy presente en el sector Ossorio del MNRT.

\section{Teología política y marxismo}

En los desgajamientos que sufrió Tacuara hacia el peronismo, se pueden encontrar las huellas de una pequeña pero significativa mutación: el pasaje de la ideología nacional-católica del MNT a un nacionalismo más secularizado, interesado en la emancipación económica y social de Argentina y, según el caso, del tercer mundo. Este viraje invirtió las premisas antimaterialistas, religiosas y culturalistas que gobernaban la construcción identitaria de la Tacuara originaria, si bien el MNA y el MNRT-Ossorio conservaron algunos tópicos antisemitas y la crítica a la cosmovisión marxista. La dimensión del discurso tacuarista intervenida por categorías religiosas configuraba una teología política, en el sentido que Carl Schmitt (2009) le daba al sostener que todos los conceptos significativos de la moderna teoría del Estado eran conceptos teológicos secularizados. ${ }^{28}$ En esta clave de lectura, si para el MNT las teorías

\footnotetext{
${ }^{26}$ R. B. B. (octubre de 1963). En torno al nacionalismo. Barricada De/ Nacionalismo Revolucionario, n. 1, p. 2. 27 R. B. B. (octubre de 1963). En torno al nacionalismo. Barricada Del Nacionalismo Revolucionario, n. 1, p. 2.

${ }^{28}$ El concepto de secularización en Schmitt es ambiguo. Si a primera vista parece reducir lo secular a lo teológico, en realidad se refiere a analogías sistemáticas entre los conceptos teológicos y el pensamiento
} 
conspirativas eran el mecanismo que explicaba el funcionamiento del nuevo orden mundial, la reformulación del combate entre el cristianismo y la modernidad constituía su horizonte de referencia político-cultural:

$1^{\circ}$ Queremos -y por ende creemos- que la verdadera antítesis en nuestro mundo no es democracia o bolchevismo, sino materialismo capitalista e idealismo occidental, basado en las virtudes milenarias de un cristianismo rejuvenecido, militante, exento de pompa estulfiante. $2^{\circ}$ Queremos -y por ende creemos- que la mejor forma de occidentalismo militante consiste en un nacionalismo cerrado, que exalte las virtudes del propio pueblo y arranque sus vicios con mano férrea. ${ }^{29}$

De acuerdo con Ezcurra Uriburu, detrás del discurso de la Guerra Fría que dividía al mundo entre demócratas y comunistas existía un antagonismo primordial, que oponía al Occidente cristiano con el materialismo ateo. Y el conflicto se terminaría por dirimir en la arena espiritual, puesto que "no hay ninguna batalla del petróleo, o del acero, o de papas, que nos pueda hacer olvidar que esas son bagatelas comparadas con el verdadero destino de nuestro pueblo y del continente". ${ }^{30}$ En el conflicto entre idealismo y materialismo, el factor religioso era central, ya que capitalismo y comunismo llevaban a la explotación y la descristianización del proletariado:

La raíz de esa injusticia estaba justamente en la concepción materialista del hombre y del cosmos. Marx no lo supo ver, pero es bueno que nosotros veamos que el único camino para alcanzar la justicia es la Caridad, y que es el único camino para alcanzar la justicia es una Cosmo-noción espiritualista y cristiana [sic]. Hay que lograr el hombre nuevo, capaz de hacer entender a la injusticia y la opresión "que los hombres que han puesto su confianza en las fuerzas del espíritu no les temen, ni pueden temerles porque lo físico es un orden inferior que obedece los dictados del Espíritu". ${ }^{31}$

En su artículo, Falchi aceptaba que Marx se había rebelado contra la opresión de los trabajadores, pero la suya no había sido una reacción ética, pues mantenía intacto el fundamento materialista de la injusticia social, destructora del alma y la persona humana. En el mismo número de Tacuara. Vocero de la Juventud Nacionalista, una columna firmada por Guillermo Malm Green criticaba la "filiación bolchevique de la reforma universitaria", y reivindicaba la organización jerárquica de la universidad medieval. Según el dirigente estudiantil:

Es evidente la necesidad de que la Universidad vuelva a Dios, introduciéndose la Universidad en la teología e introduciendo la teología en la Universidad. Fuera de los valores espirituales nada duradero se puede edificar... La crisis de la Universidad es consecuencia del igual estado de la nación. La crisis es moral. La salvación vendrá por

\footnotetext{
político moderno (Noseto, 2014).

${ }^{29}$ Ezcurra Uriburu, A. (1959). Nuestra zarza ardiente. Tacuara. Vocero De La Juventud Nacionalista, XIV (7), pp. 1-2.

${ }^{30}$ Ezcurra Uriburu, A. (1959). Nuestra zarza ardiente. Tacuara. Vocero De La Juventud Nacionalista, XIV (7), pp. 1-2.

${ }^{31}$ Falchi, C. (1960). Anticomunismo. Tacuara. Vocero De La Juventud Nacionalista, XV (8), p. 4.
} 
ese camino, ya lo dijo Péguy: "La revolución será moral, o no será". ${ }^{32}$

La cita erudita de Charles Péguy, aquel ensayista francés que se convirtió al cristianismo tras militar en el socialismo, es una buena muestra del nacionalismo cultural de corte religioso y tradicionalista que marcaba una signatura en el discurso del MNT. ${ }^{33}$ Otro ejemplo para pensar las rupturas y continuidades entre teología política y marxismo es el de la lucha de clases, tópico sobre el que no existía un posicionamiento homogéneo en la Tacuara originaria, y mucho menos en sus agrupaciones derivadas. En un artículo publicado hacia diciembre de 1963 en Tacuara. Vocero De La Juventud Nacionalista, se afirmaba:

La restauración de la Soberanía (encauzar a la Comunidad Nacional en el cumplimiento de su destino histórico) exige en la faz interna la instauración de un orden que permite integrar en la empresa nacional en forma armónica a los diversos sectores comunitarios, para lo cual es necesario acabar de raíz con las causas profundas que originan la subsistencia de divisiones artificiales de clases o partidos. La Nación es una unidad histórica, la clase una unidad económica, producto de un estado anormal. La Nación es anterior y superior a las clases. Por lo tanto, la Revolución trasciende el marco de posibilidades de ésta. ${ }^{34}$

La lógica binaria de este discurso oponía la nación a la clase como sinónimos de autenticidad frente a artificialidad, de manera semejante a lo que ocurría con otros pares como idealismo/materialismo, catolicismo/judaísmo o nacionalismo/liberalismo. Estas dicotomías producían efectos de frontera simbólicos que fundaban la identidad del MNT, y eran la forja de las diatribas contra aquella izquierda ridiculizada "por su ignorancia supina de lo nacional", o temida por la capacidad de extender sus tentáculos por el mundo. En línea con esta grilla ideológica, Antonio Mille proponía otro diagnóstico sobre la lucha de clases:

La dialéctica de la "lucha de clases" (no nos consiente la brevedad de estas líneas insistir en su falsedad), tal cual la plantea la doctrina marxista, aparece mucho más válida en las regiones donde la burguesía (entendida en sentido marxista) sigue siendo la clase económicamente dominante y el proletariado la clase económicamente disminuida. Es por eso que el camino para vencer dialécticamente al comunismo no es oponer la "dialéctica de la lucha de órbitas culturales" a la de la "lucha de clases", sino demostrar la falsedad intrínseca de la última y la necesidad de la integración de todos los productores, con sus diferentes funciones, en una recia y coherente UNIDAD NACIONAL. ${ }^{35}$

El argumento de Mille sobre la "dialéctica de la lucha de órbitas culturales" no

\footnotetext{
32 Malm Green, G. (1960). Universidad "nacional". Tacuara. Vocero De La Juventud Nacionalista, XV (8), p. 2.

${ }^{33}$ Estos argumentos se repiten en La barbarie (s.f.). Ofensiva, n. 2, p. 8, Pensamientos de Juan Vázquez de Mella y Fanjul. (agosto de 1962). Ofensiva, n .9, p. 8. Arrese, J. L. (1963). La revolución social del nacionalsindicalismo. Sindicato. Boletín de la secretaría de formación del comando Mar del Plata Movimiento Nacionalista Tacuara, n. 4. Colección 2, folios 282-287.

${ }^{34}$ Aristocracia revolucionaria (1963). Tacuara. Vocero De La Juventud Nacionalista, XVIII (s.n.), p. 3.

${ }^{35}$ Millé, A. (1961). Occidente, ¿es occidente?, Tacuara. Vocero De La Juventud Nacionalista, XVI (10), p. 2.
} 
ponía en tela de juicio la idea de crisis espiritual y revolución moral expuestas por Ezcurra Uriburu y Malm Green. Por el contrario, como era frecuente en Tacuara, impugnaba la existencia de una batalla cultural entre el Occidente capitalista y el Oriente comunista. Lo particular de este punto de vista era que las divisiones de clase no eran artificiales (lo que implicaba aceptar su realidad, aunque fuera como accidente en el cuerpo de la nación), sino una "falsedad intrínseca". Un planteo diferente realizó el tacuarista Denovi, que publicó para el boletín Ofensiva una síntesis en tres entregas del libro de Thierry Maulnier Más allá del nacionalismo. Allí sostenía que:

Si hay un hecho que desgarra profundamente la sociedad moderna este hecho es la lucha de clases. Este hecho ha sido negado sistemáticamente por el pensamiento liberalburgués que ha pregonado incansablemente que el mismo se debería a la tarea de agitadores marxistas... Reconocer el hecho de la lucha de clases es reconocer que la organización de esta sociedad es tal que una de sus facciones no puede ejercer ni acrecentar su poder sino a expensas de la segunda, y que ésta no puede defender la dignidad de sus miembros y mejorar su condición material, sino luchando contra la primera. De ahí que la terminación de la lucha de clases implique una transformación social y de ningún modo un acuerdo puramente sentimental. ${ }^{36}$

Este pasaje se opone con claridad a los conceptos vertidos más arriba en Tacuara. Vocero de la Juventud Nacionalista. Para Denovi, el liberalismo -con su defensa de la conciencia individual- y el marxismo -con su énfasis en las condiciones de vida y de trabajo- no lograrían aprehender la complejidad de lo social, ya que "ambos deducen de una de las formas de la vida humana, todas las formas de esta vida". En consecuencia, para resolver el problema de la lucha de clases era preciso "restablecer la sociedad en sus antagonismos primitivos, es decir, dar el lugar que corresponde a lo material y a la conciencia". ${ }^{37}$ En la segunda entrega, Denovi continuó su exégesis de la obra de Maulnier, concentrándose en la crítica a la tesis marxiana de la lucha de clases como motor de la historia:

El hecho de que la lucha por el poder se desarrolle hoy, principalmente, en el campo de la economía es solo consecuencia de la profunda transformación que trajo la creciente importancia de la economía, y no autoriza la temeraria afirmación de Marx de que la lucha, en la historia, ha sido siempre de esencia económica. Muy por el contrario, en tiempos en que la sociedad estuvo regida por principios religiosos o militares, la lucha se entabló en esos terrenos y ninguna influencia correspondía a la economía. ${ }^{38}$

Los conflictos de orden económico eran un caso particular de los antagonismos sociales, que habían aparecido en la época moderna. Este razonamiento historicista hacía de la lucha de clases un fenómeno contingente, despojado de los elementos

\footnotetext{
${ }^{36}$ Denovi, O. (agosto de 1962). Más allá del nacionalismo (I). El hecho de la lucha de clases. Ofensiva, n. 9 , p. 5.

${ }^{37}$ Denovi, O. (agosto de 1962). Más allá del nacionalismo (I). El hecho de la lucha de clases. Ofensiva, n. 9, p. 6.

${ }^{38}$ Denovi, O. (noviembre de 1962). Más allá del nacionalismo (I). La lucha por el poder en la sociedad. Ofensiva, n. 11, p. 14.
} 
trascendentes que le otorgaba la teoría marxista. No obstante, la postura de Denovi no estaba exenta de determinismos, ya que "la lucha por el poder en la sociedad es el motivo de los conflictos que se suscitan entre los distintos grupos que existen en todo tipo de sociedad. Ahora y siempre". ${ }^{39}$ La tercera entrega desarrolló este último punto; si la conquista del poder era el móvil de los grupos sociales a lo largo de la historia, para Maulnier, el poder social era sinónimo de poder comunitario, que se condensaba en el Estado por encima de cualquier agrupamiento clasista. De manera prescriptiva, la lucha de clases era definida como un proceso histórico que se extinguiría gracias a la acción estatal, responsable de absorber los conflictos. ${ }^{40} \mathrm{Si}$ el poder no era un objeto en disputa, sino la máxima autoridad que regulaba todas las disputas, el corolario era la conquista del Estado como fuente de soberanía nacional y garante de la armonía entre estamentos jerárquicamente organizados, un argumento contrario al fin de la sociedad de clases en el ideario marxista. En este punto, los axiomas antimaterialistas de la ideología nacional-católica, puestos en entredicho por la inclusión del concepto de lucha de clases, eran reintegrados al discurso tacuarista gracias al fetichismo del decisionismo estatal.

El MNA y la fracción Ossorio del MNRT también participaron del dilema en torno a la realidad o irrealidad de la lucha de clases. En una nota del periódico Nueva Argentina, se señalaba que la consolidación del Estado bolchevique en Rusia había convertido al marxismo en "un mero expediente ideológico" y en el "arma psicológica más importante" del expansionismo soviético. En efecto, el marxismo "rompe el frente interno de las naciones provocando la lucha de clases, a la vez que la elimina de su territorio, donde llega hasta a prohibir la huelga". ${ }^{41}$ El conflicto interclasista no era una ley histórica, sino una forma de intervención extranjera que se veía como un injerto arbitrario en el cuerpo nacional. Barricada Del Nacionalismo Revolucionario, en cambio, creía pertinente valorar los procesos históricos desde el punto de vista de la lucha de clases. ${ }^{42} \mathrm{EI}$ MNRT-Ossorio podía argumentar sobre "los conflictos que enfrentan a la burguesía y el proletariado en el seno de las comunidades nacionales", y en el mismo artículo aclarar que "nunca adherimos al patrioterismo hipócrita de la derecha ni a la sucia demagogia marxista". ${ }^{43}$ Para el grupo de Ossorio, el peronismo había demostrado que las derechas y las izquierdas eran "entes ficticios de la multifacética presencia imperialista" ${ }^{44}$ Sin embargo, este sector tomaba distancia de los "grupos reaccionarios", que habían usufructuado las tradiciones del nacionalismo:

Fueron los Genta, los Amadeo, los Goyeneche, los Meinvielle y Cía, entre otros, quienes en los hechos negaron la índole popular de nuestras luchas históricas. Claudicaban así y pasaban al bando de la triste "especialización anticomunista" sirviendo a los opresores directos del pueblo argentino. Estos personajes obstruyeron la erección de una entidad

\footnotetext{
39 Denovi, O. (noviembre de 1962). Más allá del nacionalismo (I). La lucha por el poder en la sociedad. Ofensiva, n. 11, p. 14.

${ }^{40}$ Denovi, O. (s.d.). Más allá del nacionalismo. El Estado. Ofensiva, s.d., pp. 7-8.

${ }^{41}$ Bases de la estrategia nacionalista (1965). Nueva Argentina, n. 10, p. 2.

42 Hacia un sindicalismo comunitario (octubre de 1963). Barricada Del Nacionalismo Revolucionario, n. 1, p. 3.

43 L. G. (noviembre de 1963). Nuestra revolución. Barricada Del Nacionalismo Revolucionario, n. 2, p. 3.

${ }^{44}$ Estrategia nacionalista (diciembre de 1963). Barricada Del Nacionalismo Revolucionario, n. 4, p. 3.
} 
Campos, E. J. Enemigos íntimos. Percepciones del marxismo y las izquierdas en Tacuara y sus agrupaciones derivadas

política nacionalista coherente y revolucionaria. ${ }^{45}$

El MNRT-Ossorio cuestionaba a la URSS como un capitalismo de Estado, denigraba la Revolución rusa y no ahorraba críticas al comunismo argentino, pero el anticomunismo ya no era su especialidad. Si la naturalización de conceptos marxistas significaba una ruptura con las formaciones discursivas anteriores, esta fracción del MNRT también exhibía continuidades con el nacionalismo cultural de raíces hispanistas y católicas. En su prensa se conmemoraba el Día de la Raza y se recordaba que España, gracias a la Reconquista y su fe religiosa, había logrado "rescatar de las tinieblas geográficas y espirituales, este Nuevo Mundo, para iluminarlo con la voz de la verdad e incorporarlo a la cultura de Occidente y la Historia Universal". ${ }^{46}$ En línea con el pensamiento de Maulnier, la lucha de clases era un hecho social que no era capaz de desgarrar el horizonte civilizatorio de las culturas nacionales (González, 2007). Le tocaría a la otra parte del MNRT, en definitiva, ajustar cuentas con la tradición del nacionalismo católico. Aunque este grupo compartía la idea de que "derecha e izquierda responden a consignas emanadas de imperialismos en aparente pugna", ${ }^{47}$ el primer editorial de Baxter en Tacuara del manchón se presentaba como una ruptura con la cosmovisión del llamado "viejo nacionalismo":

Argentina, para constituirse en nación, debe dejar de ser colonia, ello implica no solo lograr la independencia política (que por supuesto no tenemos), sino que además debe liberarse económicamente, ello exige una total transformación económico-social, por cuanto las actuales estructuras que tanto defienden ciertos "nacionalistas" son el instrumento de sujeción que utiliza el imperialismo, de ahí que nosotros demos fundamental importancia al estudio de los problemas económicos, un país que tiene hambre no es libre, un país monoproductor no es libre, un país cuyos recursos no están al servicio de la comunidad no es libre. ${ }^{48}$

Este discurso se distinguía de la "crisis espiritual" diagnosticada por Ezcurra Uriburu y su ironía sobre la batalla del petróleo, el acero y las papas. Para Baxter, la misión del nacionalismo era abolir las estructuras que garantizaban la opresión imperialista, por eso la "fundamental importancia" de estudiar economía, una novedad en la formación de los cuadros tacuaristas. Hacia 1959, el servicio de librería "Darwin Passaponti" del MNT ofrecía más de veinte títulos a sus militantes, entre los que se encontraban obras como Antes que la Constitución fue la Nación de Enrique P. Oses; El Estado totalitario en el pensamiento de José Antonio de José Luis de Arrese; El orgullo

\footnotetext{
${ }^{45}$ Estrategia nacionalista (diciembre de 1963). Barricada Del Nacionalismo Revolucionario, n. 4, p. 3. Para el MNRT-Ossorio y para el MNRT- Baxter-Nell, el auténtico nacionalismo revolucionario era aquel comprometido orgánicamente con el peronismo, entendido como movimiento nacional e identidad popular. Por esta razón se diferenciaban del "viejo nacionalismo".

${ }^{46}$ R.H.M. (noviembre de 1963). Vigencia de la hispanidad. Barricada Del Nacionalismo Revolucionario, n. 2, p. 2. En otra nota, la Argentina de Perón se definía en los términos del nacionalismo español, como una "Patria eterna" que brotaba del subsuelo histórico, mientras "el genio de la raza y su historia presidía el espíritu de la Revolución Nacional", ver Tercera posición (diciembre de 1963). Barricada Del Nacionalismo Revolucionario, n. 4, p. 4.

${ }^{47}$ Perón o colonia (1964). Tacuara del manchón, n. 7, p. 1.

${ }^{48}$ Baxter, J. J. (octubre de 1963). Nacionalismo. Tacuara del manchón, n. 1, p. 1.
} 
judio de H. Vries Heekelingen; La francmasonería de Alberto Palencia Zuluaga; El mito de Maritain de Juan Pablo López; y Mi lucha de Adolfo Hitler, entre otros textos políticos, históricos y religiosos. ${ }^{49}$ Del otro lado, el sector Baxter-Nell del MNRT utilizaba expresiones como "régimen explotador", "amnesia clasista" y "superestructura jurídica", ${ }^{0}$ aunque también se pueden observar continuidades con el ideario nacionalcatólico. Esto se ve en otro artículo de Baxter sobre el régimen de Ahmed Ben Bella en Argelia:

Si bien cada nación deberá recorrer su propio camino hacia la liberación, hay ciertos aspectos fundamentales en las que todas deben coincidir [sic], la construcción del socialismo es la más importante, Ben Bella lo sabe muy bien y desde la toma del poder fue dando todos los pasos para [construir] en Argelia un socialismo nacional, el cual no tiene obligatoriamente que ser marxista-leninista, tratándose de un país donde la mayoría de la población es fervientemente religiosa, y la religión es uno de los factores formativos de lo nacional. La realidad impone a los países del tercer mundo, como único camino de liberación, el socialismo. ${ }^{51}$

La Revolución argelina había instaurado un socialismo basado en la reforma agraria y la nacionalización de sectores estratégicos de la economía, pero con la peculiaridad de ser islamista y antimarxista en sus componentes identitarios (Goldar, 1972). Lo que se puede ver en estos pasajes es un esfuerzo de traducción de las categorías del nacionalismo cultural a un discurso más sensible al marxismo, que se emplea sin mayor refinación como método de análisis y programa, pero se descarta como identidad política. Esta mutación adquirió rasgos más nítidos en una entrevista del semanario Compañero a los militantes del MNRT encarcelados por el asalto al Policlínico Bancario:

La experiencia histórica nos demuestra que ante el avance amenazante del pueblo sometido, toda pugna de intereses entre las fuerzas opresoras desaparece. El proceso argentino no está exento de esta ley general, y la dinámica de las clases sociales que participan en esta realidad, no es nada más ni nada menos que esa lucha a muerte de fuerzas fatalmente antagónicas. ${ }^{52}$

Lo notable de este reportaje es la plena adopción del vocabulario marxista como herramienta de análisis (González Janzen, 1986). La estructuración clasista de la sociedad atravesaba a Argentina, al peronismo ("mal que les pese a los teóricos idealistas, que no contemplan la composición de clases en el Movimiento Nacional, son

\footnotetext{
49 Tacuara. Vocero de la juventud nacionalista (1959). XIV (7), p. 2. El boletín Ofensiva también recomendaba libros para la formación de los militantes: de 43 títulos, 18 eran catalogados en la materia "Apologética católica", 20 eran de "Historia nacional y americana" y 5 de "Política", ver Lista de libros. (noviembre de 1962). Ofensiva, n. 11, pp. 10-11.

50 Represión. Ricardo Polidoro víctima de la legislación oligárquica. (octubre de 1963). Tacuara del manchón, n. 1, p. 1.

${ }^{51}$ Baxter, J. J. (octubre de 1963). Ben Bella y el Tercer Mundo. Tacuara del manchón, n. 2, p. 4.

52 Guay, M. (8 de septiembre de 1964). Reportaje al Movimiento Nacionalista Revolucionario Tacuara. Compañero, n. 63, pp. 4-5. Archivo de Gabriel Rot. El subrayado en cursiva figura en el original. Martín Guay era un pseudónimo utilizado por el militante del peronismo revolucionario Pedro Leopoldo Barraza.
} 
sus clases las que determinan su desarrollo") e incluso al propio MNRT, ya que "su medio de acción tiene como origen la clase media baja". ${ }^{53}$ Todo el lenguaje de la nota expresaba el acercamiento a Mario Valotta, a Gustavo Rearte y a la Juventud Revolucionaria Peronista, al tiempo que tomaba distancia de los sectores que ahora se definían como un "nacionalismo de derecha", reunidos en torno a Jordán Bruno Genta, Marcelo Sánchez Sorondo y Ezcurra Uriburu. Lo característico de estos nucleamientos era la "hipertrofia de la concepción religiosa" y su "histeria antimarxista", actitudes sobre las que el MNRT trazaba una nueva frontera simbólica. ${ }^{54}$

\section{Conclusiones}

En su reseña sobre la recepción de Maulnier en la obra de Juan José Hernández Arregui, Horacio González (2007) planteó que la década del sesenta fue una época de transfiguración de valores entre marxismos y nacionalismos. La reconciliación entre unos y otros, aunque tenía importantes recorridos previos, se generalizó en América Latina después de la Revolución cubana y estuvo presente en los movimientos de descolonización del tercer mundo. Este desplazamiento de los ejes de la política revolucionaria generó síntesis particulares de nacionalismos marxistas y marxismos nacionalistas, que convergieron en la formación de una nueva izquierda (Georgieff, 2008). Del otro lado, el anticomunismo constituía un elemento central del nacionalismo de los nacionalistas que integraban Tacuara, y alcanzó una notable difusión en este período a través de una pluralidad de familias políticas (Taguieff, 1993; Bohoslavsky y Vicente, 2014; Bozza, 2016). En este nuevo escenario, el acontecer local y los alineamientos de la guerra fría llevaron a una reformulación de la tradición nacionalista heredada de la época de entreguerras. La sorpresa de García Lupo por la contigüidad entre antisemitismo, anticomunismo y antinorteamericanismo no llama tanto la atención, si se advierte la incomodidad de la derecha nacionalista frente a las oposiciones del orden bipolar. El intento de evitar la polarización de la guerra fría expresaba cierto malestar frente al hecho de que, en los años sesenta, ser anticomunista podía equivaler a quedar rotulado como socio del imperialismo norteamericano.

El comunismo era una amenaza multiforme que se extendía como una gran conspiración global en pos del gobierno universal, mecanismo que utilizaban la Tacuara originaria y el MNA para explicar el funcionamiento del nuevo orden mundial.

\footnotetext{
53 Guay, M. (8 de septiembre de 1964). Reportaje al Movimiento Nacionalista Revolucionario Tacuara. Compañero, n. 63, pp. 4-5.

${ }^{54}$ Guay, M. (8 de septiembre de 1964). Reportaje al Movimiento Nacionalista Revolucionario Tacuara. Compañero, n. 63, pp. 4-5. El tránsito de una Tacuara nacional-católica a organizaciones más secularizadas en su identidad política y -en el caso del sector Baxter-Nell del MNRT- con mayor receptividad a las ideas de izquierda, no debe confundirse con el trabajo de la memoria que realizaron algunos militantes de esa corriente, que releyeron su experiencia en la derecha nacionalista como una iniciación juvenil al activismo político con un punto de llegada en la militancia revolucionaria de los años setenta (Bardini, 2002). La necesidad de tomar distancia de las categorías nativas de los actores se advierte en las declaraciones de Joe Baxter, cuando declaraba en una entrevista: "¿Ve?... Nadie puede decir que Fidel Castro sea antisemita. Pero es un nacionalista cubano, terminó con los explotadores, y la mayoría de los judíos se tuvo que ir", ver Variante: una Tacuara izquierdista. (26 de septiembre de 1963). Primera Plana, n. 55.
} 
El horizonte cultural que daba sentido a esta trama conspirativa era el combate entre el cristianismo, última forma de "occidentalismo militante", y el materialismo encarnado por los Estados Unidos y la Unión Soviética. El MNT, el MNA y el sector Ossorio del MNRT denunciaron la complicidad entre las dos superpotencias, aunque este último criticó también la "especialización anticomunista" de la tradición nacionalista y no dejó rastros de teorías conspirativas en los documentos que se han relevado para este artículo.

Las diferencias entre el discurso de la Tacuara originaria, el MNA y el MNRT permiten suponer el tránsito de una noción trascendente de la política a otra más inmanente; de un nacionalismo de premisas culturalistas, religiosas y antimaterialistas a otro más secularizado, con centro en la emancipación económica y social. La evolución del concepto de lucha de clases en las cuatro organizaciones permite demostrar mejor este punto: en el MNT y el MNA -que percibían las tensiones de la sociedad argentina como parte de un combate entre civilizaciones-, se la representaba como un accidente que corrompía el cuerpo estable de la nación, un invento de los comunistas o -en la síntesis más elaborada de Denovi y Maulnier- como el producto de una etapa histórica que debía ser superada por la Revolución nacional-sindical. Para las dos vertientes del MNRT, la lucha de clases era un hecho social inmanente, si bien en el sector Ossorio predominaban las ideas de De Mahieu y la reivindicación de la herencia cultural hispánica. En el MNRT de Baxter y Nell -que reemplazó la doctrina comunitarista por el vocabulario marxista-, el giro fue más profundo; los tópicos del nacionalismo católico desaparecieron, se les asignó un lugar central a los procesos económicos y su dirigente más visible abjuró públicamente del pasado antisemita del grupo.

Es preciso matizar el planteo anterior para dar cuenta de la dimensión y los límites de las transformaciones. Como ha señalado Valeria Galván (2014) en sus investigaciones sobre Tacuara, sus agrupaciones derivadas y la revista Azul y Blanco, los cambios no fueron exclusivos del MNRT. A lo largo de la década de 1960, el periódico dirigido por Sánchez Sorondo pasó de una caracterización de la Cuba castrista como una genuina Revolución nacional cooptada por el comunismo, al acercamiento a posiciones lindantes con la izquierda nacional. Por otro lado, cabe señalar que la Guerra Fría no fue el único factor determinante de los alineamientos alrededor del marxismo y las izquierdas, ya que estos fueron moldeados principalmente por asuntos de política doméstica. Para varios tacuaristas, el peronismo fue el principal detonador de las rupturas del MNT, un modo de continuar la militancia nacionalista por otros medios y el prisma que refractaba sus opiniones en torno a la revolución, el marxismo y las vanguardias (Galván, 2013; Campos, 2019).

No obstante las rupturas que se señalan en este trabajo a partir del estudio de documentos poco explorados como Tacuara del manchón, varios elementos de la etapa anterior se mantuvieron, al mostrar una notable continuidad entre las ramificaciones de Tacuara a nivel iconográfico, discursivo y estético: las dos prensas del MNRT siguieron recordando a Darwin Passaponti, ${ }^{55}$ tal como había hecho durante años la Tacuara originaria. De la misma manera, la reivindicación de Hispanoamérica convivió

\footnotetext{
55 Darwin Passaponti fue un joven militante de la Alianza Libertadora Nacionalista que murió baleado durante la desconcentración de las jornadas del 17 de octubre de 1945 en la ciudad de Buenos Aires. A partir de ese momento, su figura fue entronizada como mártir del nacionalismo y del peronismo.
} 
con referencias al tercer mundo y a América Latina como términos intercambiables, junto con la repetición de figuraciones deudoras del revisionismo histórico y el criollismo, como los gauchos, las montoneras y la oligarquía mercantil porteña (Galván, 2008). Si para Schmitt todos los conceptos políticos son conceptos teológicos secularizados, es legítimo subrayar las continuidades por encima de las rupturas de las diversas Tacuaras. Un modo alternativo de pensar, como sugirió Walter Benjamin en su "Fragmento teológico-político", es afirmar que la teología y la revolución, el orden de lo mesiánico y el orden de lo profano, la redención que adviene y la búsqueda humana de felicidad, son opuestos pero a la vez convergentes. La política revolucionaria es irreductible al mesianismo premoderno, y remarcar las equivalencias entre una y otro pasa por alto la complejidad de los procesos de secularización (Cuesta, 2011). El "marxismo ateo" era el otro de los nacionalistas que querían hacer la revolución bajo el signo de Dios, y la izquierda era para Tacuara un enemigo íntimo que contribuyó a modelar su identidad, a tal punto que, en algunos casos, los antagonistas se convirtieron en aliados.

\section{Referencias bibliográficas}

1. Acha, O. (2014, 18 de septiembre). El peronismo y la forja del anticomunismo obrero [ponencia]. IV Congreso de Estudios sobre el Peronismo. Universidad Nacional de Tucumán, San Miguel de Tucumán, Argentina.

2. Bardini, R. (2002). Tacuara. La pólvora y la sangre. Océano.

3. Besoky, J. L. (2017). El discurso anticomunista en las publicaciones del peronismo de derecha. Claves. Revista de Historia, 3 (5), 129-153. https://doi.org/10.25032/crh.v3i5.156

4. Bohoslavsky, E. y Vicente, M. (2014). Sino el espanto: Temas, prácticas y alianzas de los anticomunismos de derecha en Argentina entre 1955 y 1966. Anuario del Instituto de Historia Argentina, 14, 1-17. https://www.anuarioiha.fahce.unlp.edu.ar/article

5. Bozza, J. A. (2016, 5 de diciembre). La sombra de la Revolución Cubana. Anticomunismo y nueva izquierda en la Argentina de los primeros años sesenta [ponencia]. IX Jornadas de Sociología de la Universidad Nacional de La Plata. La Plata, Argentina.

6. Campos, E. (2016). Entrevista a Alfredo Ossorio: de la derecha nacionalista a la izquierda peronista. En P. Pozzi (Coord.) Rebeldes e inconformistas. Procesos de politización y rebelión en América Latina (pp. 75-98). Imago Mundi.

7. Campos, E. (2019). De aristócratas revolucionarios a vanguardia de clase. La revisión del peronismo en Tacuara y sus agrupaciones derivadas. Prohistoria. Historia, políticas de la historia, 32, 155-181. 
Campos, E. J. Enemigos íntimos. Percepciones del marxismo y las izquierdas en Tacuara y sus agrupaciones

https://doi.org/10.35305/prohistoria.vi.1107

8. Cuesta, M. (2011). Fragmento teológico-político de Walter Benjamin: una interpretación. Analecta. Revista de Humanidades, 5, 59-74.

9. Galván, M. V. (2008). El Movimiento Nacionalista Tacuara y sus agrupaciones derivadas: una aproximación desde la historia cultural [tesis de maestría, Universidad Nacional de General San Martín, tesis no publicada].

10. Galván, M. V. (2013). Militancia nacionalista en la era posperonista: las organizaciones Tacuara y sus vínculos con el peronismo. Nuevo Mundo Mundos Nuevos. https://doi.org/10.4000/nuevomundo.65364

11. Galván, M. V. (2014). Influencias de la Guerra Fría en el discurso nacionalista argentino. El retrato de los conflictos internacionales en el Semanario Nacionalista Azul y Blanco. OPSIS, 14, 205-224. https://doi.org/10.5216/o.v14iEspecial.30400

12. García Lupo, R. (1962). Diálogo con los jóvenes fascistas. En La rebelión de los generales. Proceso.

13. Georgieff, G. (2008). Nación y revolución. Itinerarios de una controversia en Argentina (1960-1970). Prometeo.

14. Goldar, E. (1972). La Revolución argelina. Centro Editor de América Latina.

15. González, H. (2007). Restos pampeanos: ciencia, ensayo y política en la cultura argentina del siglo XX. Colihue.

16. González Janzen, I. (1986). La Triple A. Contrapunto.

17. Gutman, D. (2003). Tacuara. Historia de la primera guerrilla urbana argentina. Vergara.

18. Jameson, F. (1995). La estética geopolítica. Cine y espacio en el sistema mundial. Paidós.

19. Noseto, L. (2014). Lecturas de Carl Schmitt. Forma y contenido de la teología política. Instituto de Investigaciones Gino Germani.

20. Padrón, J. M. (2017). ¡Ni yankis ni marxistas! Nacionalistas: Nacionalismo, militancia y violencia política. El caso del Movimiento Nacionalista Tacuara en la Argentina (1955-1966). Universidad Nacional de La Plata/Universidad Nacional de Misiones/Universidad Nacional de General Sarmiento. 
Campos, E. J. Enemigos íntimos. Percepciones del marxismo y las izquierdas en Tacuara y sus agrupaciones

21. Piglia, R. (2001). Plácidos domingos. Fundación Start.

22. Ruffini, M. (2016). Poder y violencia en Argentina durante la década de 1960. La trama del atentado al ex presidente Arturo Frondizi. Nuevo Mundo Mundos Nuevos. https://doi.org/10.4000/nuevomundo.69324

23. Schmitt, C. (2009). Teología política. Trotta.

24. Taguieff, P. (1993). El nacionalismo de los 'nacionalistas'. Un problema para la historia de las ideas políticas en Francia. En G. Delanoi y P. Taguieff (Comps.) Teorías del nacionalismo (pp. 63-180). Paidós.

25. Taïeb, E. (2010). Logiques politiques du conspirationnisme. Sociologie et sociétés, 42 (2), pp. 265-289. https://doi.org/10.7202/045364ar 